\title{
Effects of different vardenafil doses on bone healing in a rat fracture model
}

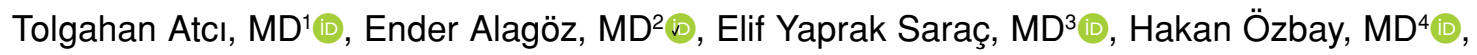 \\ Mustafa Fatih Daşcı, $\mathrm{MD}^{5} \oplus$, Abdurrahman Acar, $\mathrm{MD}^{6} \oplus$, Derya Karabulut, $\mathrm{MD}^{7}{ }^{\oplus}$, \\ Mehmet Akif Güleç, MD²0 \\ 'Department of Orthopedics and Traumatology, Sorgun State Hospital, Yozgat, Turkey \\ ${ }^{2}$ Department of Orthopedics and Traumatology, Health Sciences University, Bağcılar Training and Research Hospital, Istanbul, Turkey \\ ${ }^{3}$ Molecular Biology Genetics and Biotechnology, Istanbul Technical University, Istanbul, Turkey \\ ${ }^{4}$ Department of Orthopedics and Traumatology, Ağrı State Hospital, Ağrı, Turkey \\ ${ }^{5}$ Department of Orthopedics and Traumatology, Cihanbeyli State Hospital, Konya, Turkey \\ ${ }^{6}$ Department of Orthopedics and Traumatology, Şırnak State Hospital, Şırnak, Turkey \\ ${ }^{7}$ Mechanical Engineering, Istanbul University-Cerrahpaşa Faculty of Engineering, Istanbul, Turkey
}

Fracture healing is a dynamic process affected by many systemic and local factors. ${ }^{[1]}$ It is vital for fracture healing that the blood supply is sufficient for crucial factors such as hormones, growth factors, and minerals to reach the fracture site. ${ }^{[1]}$ Reduced fracture vascularity may result in a delayed bone union and atrophic non-union. Despite the developments in medical treatment methods, challenges related to the bone union are observed in 2 to $30 \%$ of fractures. ${ }^{[2]}$

Phosphodiesterase-5 (PDE5) enzyme is abundantly found in the skeletal muscle cells,

Received: May 11, 2021

Accepted: May 17, 2021

Published online: June 11, 2021

Correspondence: Ender Alagöz, MD. SBÜ Bağcılar Eğitim ve Araştırma Hastanesi Ortopedi ve Travmatoloji Kliniği,

34200 Bağcılar, İstanbul, Türkiye.

E-mail: enderalagoz@yahoo.com

Doi: $10.52312 / j d r s .2021 .72$

Citation: Atcı T, Alagöz E, Yaprak Saraç E, Özbay H, Dascı MF, Acar $A$, et al. Effects of different vardenafil doses on bone healing in a rat fracture model. Jt Dis Relat Surg 2021;32(2):313-322.

(O2021 All right reserved by the Turkish Joint Diseases Foundation

This is an open access article under the terms of the Creative Commons Attribution-NonCommercial License, which permits use, distribution and reproduction in any medium, provided the original work is properly cited and is not used for commercial purposes (http://creativecommons.org/licenses/by-nc/4.0/).

\section{ABSTRACT}

Objectives: We aimed to investigate the radiological, biomechanical, histopathological, histomorphometric, and immunohistochemical effects of different doses of vardenafil on fracture healing.

Materials and methods: Fifty-one rats were divided into three groups. Group V5 was given $5 \mathrm{mg} / \mathrm{kg} / \mathrm{day}$ of vardenafil; Group $\mathrm{V} 10$ was given $10 \mathrm{mg} / \mathrm{kg} /$ day of vardenafil; and the control group was given the same volume of saline. Six rats from each group were sacrificed on Day 14 (early period) and the remaining rats were sacrificed on Day 42 (late period). Callus/femoral volume and bone mineral density were measured using microcomputed tomography. Five femurs from each group in the late period were examined by biomechanical tests. In addition to the histopathological and histomorphometric evaluations, immunohistochemical analyses were performed to examine the levels of inducible nitric oxide synthase (iNOS), transforming growth factor-3 (TGF- $\beta 3$ ), and nuclear factor kappa B (NF- $\mathrm{kB}$ ) proteins.

Results: Both doses of vardenafil increased primary bone volume and maximal bone fracture strength in late period, compared to the control group $(p<0.05)$. Histological healing scores of vardenafil groups were significantly higher in early period $(\mathrm{p}<0.001)$. While cartilaginous callus/total callus ratio in early period was higher, callus diameter/femoral diameter ratio in late period was lower in vardenafil groups $(\mathrm{p}<0.01)$. The $\mathrm{NF}-\kappa \mathrm{B}$ immunopositivity in V10 group decreased in early period, compared to control group $(\mathrm{p}<0.001)$. The TGF- $\beta 3$ and iNOS immunopositivity increased in both V5 and V10 groups, compared to the control group in early period, but returned to normal in late period.

Conclusion: During the first period of fracture healing process in which vasodilation is mostly required with increasing inflammation, vardenafil has ameliorating effects on the bone union and supports fracture healing.

Keywords: Bone healing, femur, rat, vardenafil. 
vascular smooth muscle cells, and pulmonary vascular structures. The PDE5A3, an isoform of the PDE5 enzyme, is specific for the smooth muscle cells and involved in the regulation of the contractions of vascular smooth muscle cells. ${ }^{[3,4]}$ The PDE5 enzyme inhibitor is a type of targeted therapy used in many diseases such as erectile dysfunction, symptoms of benign prostatic hyperplasia, chronic heart failure, pulmonary hypertension, and essential hypertension. ${ }^{[5,6]}$ As a PDE5 inhibitor, vardenafil acts by blocking the degradative action of cGMP-specific PDE5, resulting in an increase in the intracellular levels of 3-5-cyclic guanosine monophosphate (cGMP), an essential secondary messenger, and has been demonstrated to be a critical stimulator of angiogenesis through the upregulation of pro-angiogenic factors and the control of cGMP concentration. ${ }^{[7]}$ Recent studies have shown that PDE5 inhibitors have beneficial effects on the fracture healing by enhancing bone formation in experimental animal models. ${ }^{[8,9]}$ This may be related to the beneficial effect of PDE5 inhibitors on vasodilatation, angiogenesis and nitric oxide $(\mathrm{NO}) / \mathrm{cGMP} /$ protein kinase $\mathrm{G}$ (PKG) signaling pathway. ${ }^{[10]}$

Although there are limited studies examining the effects of different PDE5 inhibitors on the fracture union in the literature, ${ }^{[8-10]}$ there are no available data regarding vardenafil and its different doses in fracture healing. In the present study, therefore, we aimed to investigate the radiological, biomechanical, histopathological, histomorphometric, and immunohistochemical effects of different doses of vardenafil on the bone healing process in a rat femur fracture model.

\section{MATERIALS AND METHODS}

This study was approved by the Bağclar Training and Research Hospital Ethics Committee (No: 2017/2) for animal experiments and was conducted in accordance with the principles of the World Medical Association statement on animal use in biomedical research.

\section{Animals}

Fifty-four Sprague-Dawley male rats, weighing an average of $370 \mathrm{~g}$ (range, 348 to $392 \mathrm{~g}$ ), were used in the study. One animal from each group was excluded for various reasons (one animal died from both the low- and high-dose vardenafil groups, and one animal from control group did not gain enough weight). During the study, unlimited tap water and standard rodent feed were given to the rats. The animals were followed throughout the entire procedure at $22^{\circ} \mathrm{C}$, in cycles of $12 \mathrm{~h}$ light and $12 \mathrm{~h}$ dark. The rats were randomly divided into three groups ( $\mathrm{n}=17$ ): control, low dose of vardenafil (V5), and high dose of vardenafil (V10). By the oral gavage method, the animals in the V5 and V10 groups were administered a vardenafil solution at a dose of $5 \mathrm{mg} / \mathrm{kg} /$ day, and $10 \mathrm{mg} / \mathrm{kg} /$ day, respectively and the animals in control group were administered the same volume of saline solution, until the day of sacrification.

\section{Surgery}

Fracture models were established by the osteotomy of right femurs and applying Kirschner wire (K-wire) fixation. Before surgery, $8 \mathrm{mg} / \mathrm{kg}$ of gentamicin (Genta ${ }^{\circledR}$, İ.E. Ulagay, Istanbul, Turkey) was administered subcutaneously as a single-dose prophylaxis. Intraperitoneal injection of $80 \mathrm{mg} / \mathrm{kg}$ ketamine hydrochloride (Ketalar ${ }^{\circledR}$, Pfizer, Istanbul, Turkey) and intraperitoneal injection of $5 \mathrm{mg} / \mathrm{kg}$ xylazine hydrochloride (Rompun ${ }^{\circledR}$, Bayer, Istanbul, Turkey) were used for anesthesia. The femur body was reached by passing through the vastus lateralis and rectus femoris muscles with a $3-\mathrm{cm}$ lateral longitudinal incision of the right thigh. Transverse osteotomy was performed in the middle of the femur by using a micro-cutter. Using an electrical driller motor, a 1.2-mm K-wire was moved antegradely through the distal fragment and pulled out from the knee area. The K-wire was, then, pulled distally until the wire disappeared at the fracture line. After the reduction, the K-wire was moved retrogradely and pushed into the intramedullary channel of the proximal fragment. The stability of fracture line was checked, and a care was taken to avoid a distraction in the osteotomy line. After the procedure, the fascia and the skin were sutured and closed separately.

\section{Radiological analysis}

The newly formed callus volume $\left(\mathrm{mm}^{3}\right)$ and bone mineral density (BMD) $\left(\mathrm{g} / \mathrm{cm}^{3}\right)$ of all femur specimens were measured with a microcomputed tomography (mCT) device (Bruker Micro-CT SkyScan 1174, MA, USA). For each specimen of the right femur, firstly $\mathrm{mCT}$ scanogram images were obtained and, then, the evaluation area of $7.5 \mathrm{~mm}$ above and below of the fracture line was evaluated and the callus volumes were calculated in the examination area of $15 \mathrm{~mm}$ in total. The BMD analyses were performed using $0.25 \mathrm{~g} / \mathrm{cm}^{3}$ and $0.75 \mathrm{~g} / \mathrm{cm}^{3}$ of calcium hydroxyapatite calibration rods. The analysis of images was carried out using the Bruker CT analyzer program and the images were reconstructed in three dimensions (3D). 


\section{Biomechanical analysis}

Three-point bending test was applied to determine the biomechanical durability of fracture healing at the level reached at the end of six weeks. Biomechanical tests were carried out using a tester device (Instron 5982, MA, USA) with a load capacity of $100 \mathrm{kN}$, a sampling frequency of $1 \mathrm{kHz}$, and a force measurement accuracy of $\pm 0.5 \%$. The right femoral bones were positioned horizontally on the measuring device by their fronts facing upward, and the tests were carried out to ensure that the applied force reached the axis perpendicular to the fracture line. The distance between the supports was the same for each right femur bone, measured as $10 \mathrm{~mm}$. The bones were bent, until a fracture occurred at a rate of $5 \mathrm{~mm} / \mathrm{s}$. The force and deflection data were recorded simultaneously by a computer program (Instron Blue Hill 3, MA, USA) that was compatible with the test device used. The breaking force was determined as the highest point (Fmax) of the force curve.

\section{Histopathological analysis}

All femurs cleaned from their muscles were fixed in a $10 \%$ buffered formaldehyde solution for a week. After fixation, they were decalcified in $10 \%$ formic acid solution for three days and, then, taken macroscopically into the cassettes and dehydrated by serial alcohol sets, acetone, xylene, paraffin stages in a closed system of tissue processor device. Subsequently, a paraffin blocking was performed, longitudinal sections of 3 to $4 \mu \mathrm{m}$ were taken and stained by hematoxylin-eosin (H-E) and Masson's trichrome. A light microscope (Olympus BX61; Olympus Corp., Tokyo, Japan) with a camera attachment (Olympus DP72; Olympus Corp., Tokyo, Japan) was used for histopathological examination and photographing. At least five sections were randomly selected and scored according to a numerical scoring system for callus healing and according to the histological healing scale between 1 and 10 determined by a histologist and pathologist, as previously described. ${ }^{[11]}$ Inflammation scoring was evaluated by a pathologist under the light microscope according to the lymphocyte infiltration and scored between 0 and 3 by the same histologist as previously described. ${ }^{[12]}$

\section{Histomorphometry}

Quantitative analysis of serial sections of the fracture area was performed with Olympus DP72 image analysis software as previously described. ${ }^{[13]}$ Total callus consisting of the bone (ossified tissue), cartilage and fibrous callus was measured. The ratio of the cartilaginous callus area-to-total callus area and the ratio of the total callus diameter-to-femoral bone diameter were calculated in fracture areas obtained at the end of two weeks. Since the cartilaginous callus disappeared in the samples taken at the end of six weeks, only the ratio of the total callus diameter-tofemoral bone diameter was calculated. ${ }^{[3]}$

\section{Immunohistochemical analysis}

Immunohistochemical staining of streptavidinbiotin-peroxidase method was applied on the femoral sections using monoclonal and polyclonal antibodies labeled to show inducible nitric oxide synthase (iNOS), transforming growth factor- $\beta 3$ (TGF- $\beta 3$ ), and nuclear factor kappa B (NF- $\kappa \mathrm{B})$ proteins in fracture healing. Five regions showing positive immunolabeling with relevant antigens were analyzed in terms of staining intensity by using semi-quantitative modified H-SCORE. Scores between 0 and 300 were given by two researchers for five regions, and the scores were averaged. Femoral localizations of staining were determined, and the changes in protein expression and regional differences were detected semiquantitatively. ${ }^{[14]}$

\section{Statistical analysis}

Statistical analysis was performed using the GraphPad Instat version 3.06 software (GraphPad Inc., CA, USA). Descriptive data were expressed in mean \pm standard error (SE). The means of two or
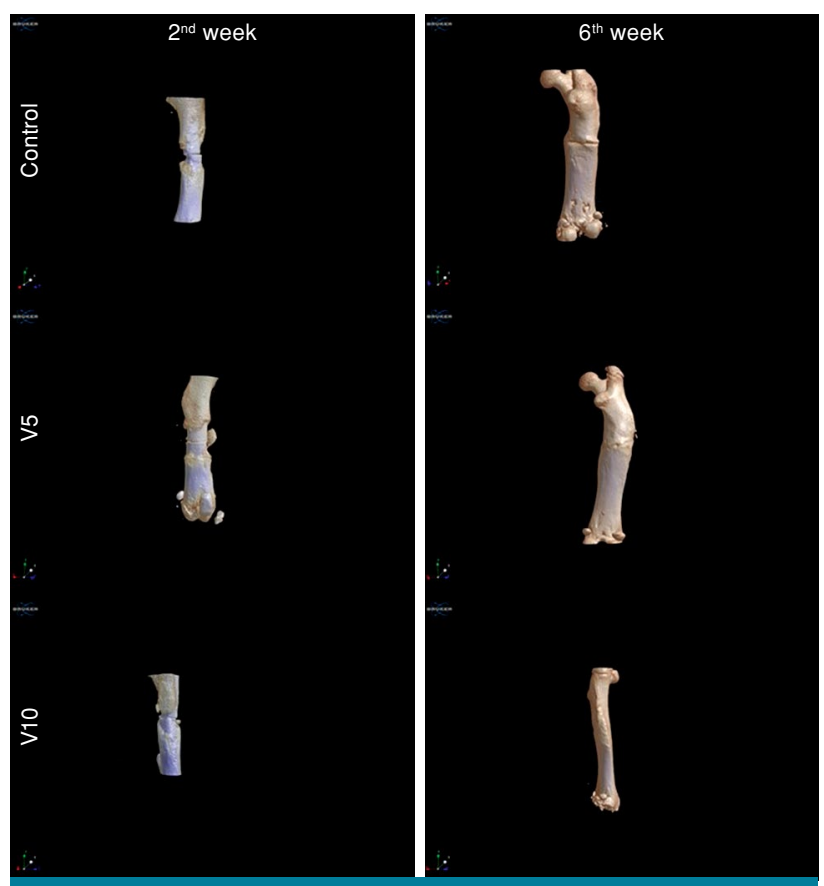

FIGURE 1. Microcomputed tomography images obtained at two and six weeks in the control, V5 (Vardenafil $5 \mathrm{mg}$ ) and V10 (Vardenafil $10 \mathrm{mg}$ ) groups. 


\begin{tabular}{|c|c|c|c|}
\hline $\begin{array}{l}\text { The callus volun } \\
\text { and six we }\end{array}$ & $\begin{array}{l}\text { ured by microc } \\
\text { g) and V10 (Ve }\end{array}$ & $\begin{array}{l}\text { iputed tomogra } \\
\text { enafil } 10 \mathrm{mg} \text { ) gre }\end{array}$ & $\begin{array}{l}\text { y at two } \\
\text { ps }\end{array}$ \\
\hline & $2^{\text {nd }}$ week & $6^{\text {th }}$ week & \multirow[b]{2}{*}{$p$ value } \\
\hline & Mean \pm SE & Mean \pm SE & \\
\hline \multicolumn{4}{|c|}{ Callus volume/bone volume $\left(\mathrm{mm}^{3} / \mathrm{mm}^{3}\right)$} \\
\hline Control group & $1.41 \pm 0.22$ & $0.69 \pm 0.05 t$ & 0.0022 \\
\hline V5 group & $1.35 \pm 0.11$ & $0.79 \pm 0.06^{*}, \dagger$ & 0.0022 \\
\hline V10 group & $1.42 \pm 0.15$ & $0.80 \pm 0.04^{*}, \dagger$ & 0.0043 \\
\hline$p$ value & 0.964 & 0.022 & \\
\hline \multicolumn{4}{|l|}{$\operatorname{BMD}\left(\mathrm{g} / \mathrm{cm}^{3}\right)$} \\
\hline Control group & $0.949 \pm 0.013$ & $1.051 \pm 0.004 \dagger$ & 0.0022 \\
\hline V5 group & $0.974 \pm 0.009$ & $1.051 \pm 0.008 \dagger$ & 0.0022 \\
\hline V10 group & $0.957 \pm 0.013$ & $1.058 \pm 0.006 \dagger$ & 0.0022 \\
\hline$p$ value & 0.373 & 0.665 & \\
\hline
\end{tabular}

more independent groups were compared using the one-way analysis of variance (ANOVA) test, and the differences between groups were compared using the Tukey-Kramer multiple comparison test and the Kruskal Wallis comparison test. Values of $p<0.05$, $\mathrm{p}<0.01$, and $\mathrm{p}<0.001$ were considered statistically significant for different groups.

\section{RESULTS}

\section{Radiological findings}

The images obtained from control, V5, and V10 groups by mCT scanning performed following the second and sixth weeks of the fracture healing processes are presented in Figure 1. When the ratio of callus volumes to the cortical bone volume in the fracture area was examined, there was no significant difference among the groups at two weeks, while the rates were significantly higher in the vardenafil groups at six weeks $(\mathrm{p}<0.05)$. At six weeks, as the fracture healing progressed, the ratio of callus volume to bone volume also decreased significantly $(\mathrm{p}<0.01)$ (Table I).

There was no statistically significant difference among the groups in terms of BMD results $\left(\mathrm{g} / \mathrm{cm}^{3}\right)$ both at two and six weeks. However, the BMD values increased significantly at six weeks, compared to those of the second week $(p<0.01)$ (Table I).

\section{Biomechanical findings}

The mean maximum fracture strength (Fmax) value obtained from the right femoral bones of the V5 group was greater than the values obtained from the V10 and control groups (Figure 2). While the highest fracture strength value was obtained from V5 group, the lowest fracture strength value was obtained from the control group $(\mathrm{p}<0.05)$. Although there was a difference between the Fmax values of V5 and V10 groups, it did not reach statistical significance $(p>0.05)$ (Figure 2$)$.

\section{Histopathological findings}

Extensive soft callus areas in two-week images of femoral fractures could be differentiated by the cartilaginous callus, as well as the inflammation and infiltration areas (Figure 3). In the six-week

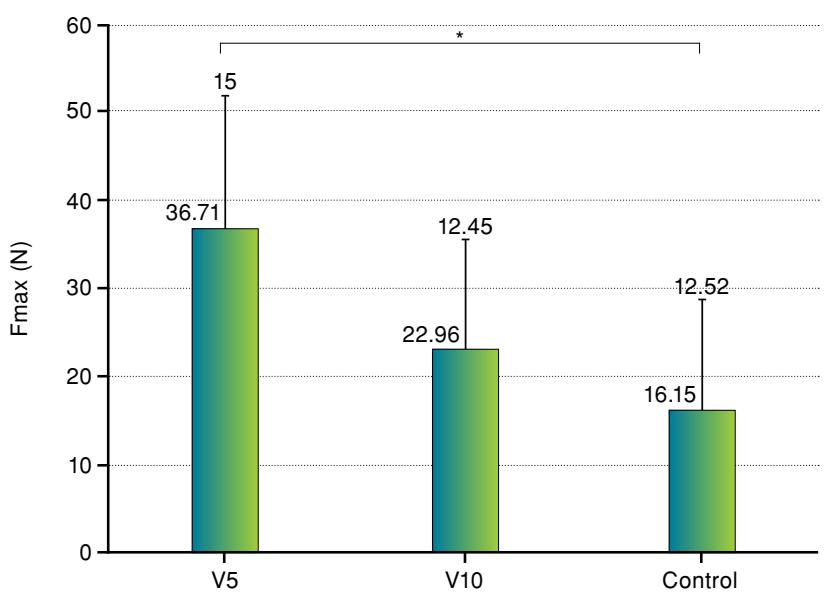

FIGURE 2. The mean values of maximum fracture force (Fmax) of the control, V5 (Vardenafil $5 \mathrm{mg}$ ) and V10 (Vardenafil $10 \mathrm{mg}$ ) groups.

${ }^{*} p<0.05$ vs control group. 

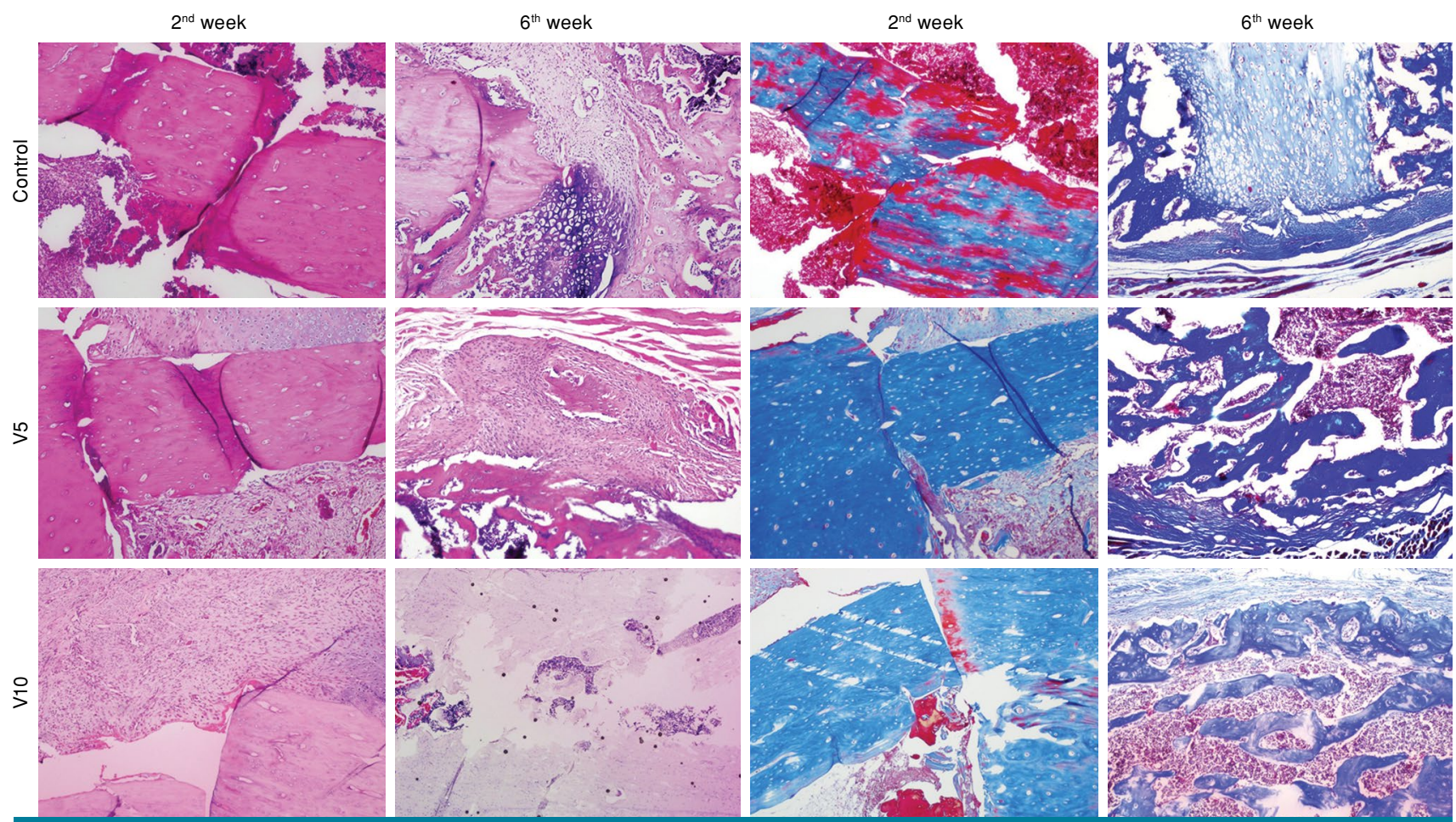

FIGURE 3. The microscopical images of bone healing at two and six weeks in the control, V5 (Vardenafil 5 mg) and V10 (Vardenafil $10 \mathrm{mg}$ ) groups, hematoxylin-eosin (first and second column) and Masson's trichrome (third and fourth column), 10× magnification.

images, the primary bone regions were also noted, as well as the hard callus formed with the reduced two-dimensional callus diameter (Figure 3).

Histological healing scores are presented in Table II. The scores of fracture healing increased significantly in the vardenafil groups at two weeks, compared to the control group $(\mathrm{p}<0.01)$; however, there was no statistically significant difference between the dose groups. At six weeks, only the increase in the V10 group was significantly higher, compared to the control and V5 groups $(p<0.05)$, although there was no significant difference between the control and V5 groups.

\begin{tabular}{|c|c|c|c|}
\hline \multicolumn{4}{|c|}{ TABLE II } \\
\hline & $2^{\text {nd }}$ week & $6^{\text {th }}$ week & \\
\hline & Mean \pm SE & Mean $\pm S E$ & $p$ value \\
\hline \multicolumn{4}{|c|}{ Histological healing score } \\
\hline Control group & $1.17 \pm 0.41$ & $6.50 \pm 0.84 \rrbracket$ & 0.0024 \\
\hline V5 group & $4.83 \pm 1.60^{\star *}$ & $7.67 \pm 1.51 \dagger$ & 0.0193 \\
\hline V10 group & $4.67 \pm 2.07^{\star \star}$ & $8.67 \pm 0.82^{*}, \ddagger$ & 0.0055 \\
\hline$p$ value & 0.0011 & 0.013 & \\
\hline \multicolumn{4}{|c|}{ Inflammation score } \\
\hline Control group & $3.00 \pm 0.0$ & $0.67 \pm 0.21 \rrbracket$ & 0.0001 \\
\hline V5 group & $0.17 \pm 0.17^{\star \star \star}$ & $0.17 \pm 0.17$ & 1.00 \\
\hline V10 group & $1.00 \pm 0.44^{\star \star \star}$ & $0 \pm 0^{*}$ & 0.076 \\
\hline$p$ value & $<0.0001$ & 0.045 & \\
\hline
\end{tabular}




\begin{tabular}{|c|c|c|c|}
\hline \multicolumn{4}{|c|}{$\begin{array}{l}\text { TABLE III } \\
\text { The histomorphometric findings measured at two and six weeks in the control, } \\
\text { V5 (Vardenafil } 5 \mathrm{mg} \text { ) and V10 (Vardenafil } 10 \mathrm{mg} \text { ) groups }\end{array}$} \\
\hline & \multicolumn{2}{|c|}{$2^{\text {nd }}$ week } & $6^{\text {th }}$ week \\
\hline & $\begin{array}{l}\text { Cartilaginous callus } \\
\text { area/total callus area }\end{array}$ & $\begin{array}{c}\text { Total callus } \\
\text { diameter/femoral diameter }\end{array}$ & $\begin{array}{c}\text { Total callus } \\
\text { diameter/femoral diameter }\end{array}$ \\
\hline$\%$ & Mean \pm SE & Mean \pm SE & Mean $\pm S E$ \\
\hline Control group & $47.47 \pm 4.67$ & $43.85 \pm 4.08$ & $17.85 \pm 4.45$ \\
\hline V5 group & $82.68 \pm 5.56^{\star *}$ & $56.55 \pm 6.70$ & $6.39 \pm 1.55^{*}$ \\
\hline V10 group & $90.90 \pm 4.08^{* *}$ & $47.09 \pm 4.79$ & $4.84 \pm 0.58^{*}$ \\
\hline$p$ value & $<0.0001$ & 0.153 & 0.0088 \\
\hline
\end{tabular}

Considering the inflammation scores, inflammation in the vardenafil groups was significantly reduced, compared to the control group $(\mathrm{p}<0.001)$, and the least inflammation was observed in the V5 group; however, there was no significant difference in the scores of dose groups for both periods (Table II).
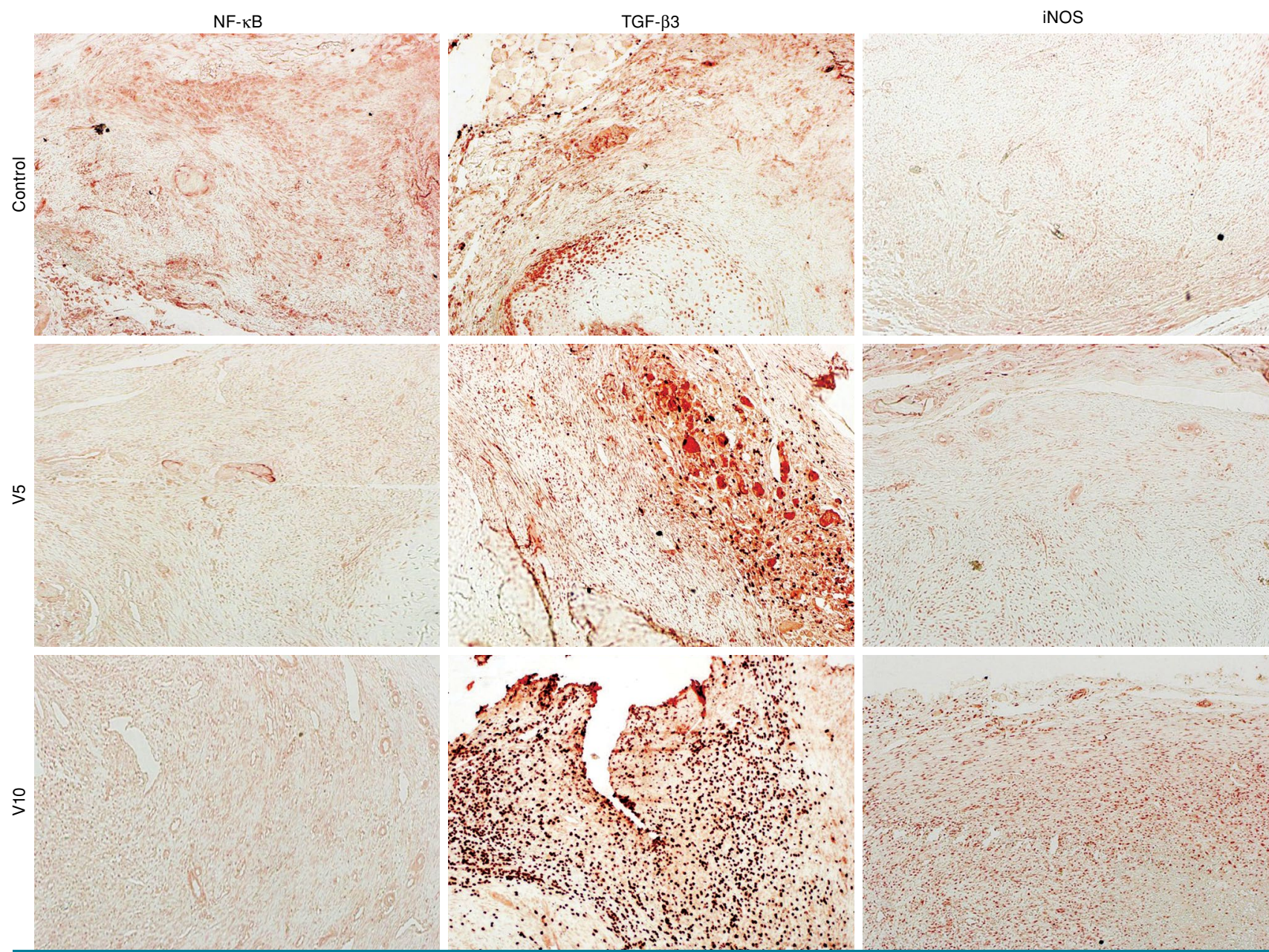

FIGURE 4. The microscopical images of immunohistochemical analysis of nuclear factor kappa B (NF-kB), transforming growth factor- $\beta 3$ (TGF- $\beta 3$ ), and inducible nitric oxide synthase (iNOS) at two weeks in the control, V5 (Vardenafil 5 mg) and V10 (Vardenafil $10 \mathrm{mg}$ ) groups, $10 \times$ magnification. 


\begin{tabular}{|c|c|c|c|}
\hline \multicolumn{4}{|c|}{$\begin{array}{c}\text { TABLE IV } \\
\text { NF-kB, TGF- } \beta 3 \text { and iNOS immunoreactivity at two and six weeks in the control, } \\
\text { V5 (Vardenafil } 5 \mathrm{mg} \text { ) and V10 (Vardenafil } 10 \mathrm{mg} \text { ) groups }\end{array}$} \\
\hline & $2^{\text {nd }}$ week & $6^{\text {th }}$ week & \\
\hline & Mean $\pm S E$ & Mean $\pm S E$ & $p$ value \\
\hline \multicolumn{4}{|l|}{$N F-\kappa B$} \\
\hline Control group & $94.00 \pm 8.72$ & $70.00 \pm 12.25$ & 0.149 \\
\hline V5 group & $66.67 \pm 10.85$ & $65.00 \pm 21.16$ & 0.971 \\
\hline V10 group & $36.67 \pm 6.67^{* *}$ & $55.00 \pm 8.54$ & 0.110 \\
\hline$p$ value & 0.0007 & 0.820 & \\
\hline \multicolumn{4}{|l|}{ TGF- $\beta 3$} \\
\hline Control group & $206.00 \pm 8.94$ & $120.00 \pm 20.0 \dagger$ & 0.008 \\
\hline V5 group & $275.00 \pm 9.22^{* *}$ & $83.33 \pm 16.67 \dagger$ & 0.002 \\
\hline V10 group & $288.33 \pm 8.33^{* *}$ & $75.00 \pm 20.45 \dagger$ & 0.002 \\
\hline$p$ value & $<0.0001$ & 0.284 & \\
\hline \multicolumn{4}{|l|}{ iNOS } \\
\hline Control group & $76.00 \pm 10.30$ & $100.00 \pm 22.36$ & 0.674 \\
\hline V5 group & $125.00 \pm 7.64^{*}$ & $87.50 \pm 22.13$ & 0.335 \\
\hline V10 group & $141.67 \pm 9.46^{* *}$ & $63.33 \pm 17.26 \dagger$ & 0.002 \\
\hline$p$ value & 0.0001 & 0.188 & \\
\hline
\end{tabular}

\section{Histomorphometric findings}

The ratio of cartilaginous callus area-to-total callus area in the fractures at two weeks was found to significantly increase in the V5 and V10 groups, compared to the control group $(\mathrm{p}<0.001)$. However, no significant difference in the ratio of total callus diameter-to-femoral bone diameter was detected among the groups (Table III). Since the cartilaginous callus area completely disappeared in the fracture area at six weeks, only the ratio of the total callus diameter-to-femoral bone diameter was calculated for histomorphometric analysis and significant decreases were detected in this ratio at six weeks, compared to the control group $(\mathrm{p}<0.01)$ which gradually decreased by increasing dose of vardenafil (Table III).

\section{Immunohistochemical findings}

In the comparison of immunostainings between the groups at two weeks, the lowest NF-kB immunoreactivity was observed in the V10 group and, as the dose of vardenafil increased, the immunopositivity decreased $(\mathrm{p}<0.001)$ (Figure 4$)$. Similarly, at six weeks, the immunopositivity of NF-kB in the femoral fracture areas decreased, as the dose increased, although this difference was not statistically significant (Table IV).
An increasing TGF- $\beta 3$ immunopositivity was observed in the vardenafil-administered rats at two weeks (Figure 4), and this increase was statistically significant, compared to the control group $(\mathrm{p}<0.001)$. No such difference was found among the groups at six weeks. On the other hand, when the secondand sixth-week groups were compared in terms of TGF- $\beta 3$ immunoreactivity, a dramatic decrease was noted at six weeks $(\mathrm{p}<0.01)($ Table IV).

A significantly increased iNOS immunopositivity was observed in the vardenafil- administered rats at two weeks, compared to the control group ( $<<0.01$ for V5 and $\mathrm{p}<0.001$ for V10 group) (Figure 4). Comparing the immunoreactivities at two and six weeks, a statistically significant decrease was observed in the immunopositivity of V10 group at six weeks, compared to the second-week measurement $(\mathrm{p}<0.01)$.

\section{DISCUSSION}

Recently, the positive contribution of PDE5 inhibitors, used in the treatment of erectile dysfunction, to the fracture healing has been demonstrated in various studies. ${ }^{[3,15]}$ It has been demonstrated that sildenafil and tadalafil, two of PDE5 inhibitors, are able to accelerate the healing of fracture defects by 
supporting the formation of bony fracture bridges and exert this beneficial effect by increasing nitric oxide synthase (NOS) enzymes. ${ }^{[3,15]}$ Dinçel et al. ${ }^{[8]}$ evaluated the effects of sildenafil and pentoxifylline on the fracture union biomechanically, histologically, and radiologically and found that sildenafil had positive effects on early and late fracture union. In our study, we demonstrated that vardenafil, a more potent and selective PDE5 inhibitor than sildenafil, accelerated the fracture union beginning from the early stages, even at low doses in our rat model.

Although there are radiological evaluations of fracture healing based on the direct X-ray findings, there is evidence that these radiological evaluations and measurements are not sufficiently objective in examining the fracture healing and show distinctions in evaluation between individuals. ${ }^{[16,17]}$ In a study by Rajfer et al., ${ }^{[18]}$ a quantitative $\mathrm{mCT}$ was used to investigate the effect of tadalafil, another PDE5 inhibitor, on the fracture healing in a rat model established by an open femoral osteotomy, and the mineral content, mineralized callus area and BMD were measured. In the osteotomy site, the callus volumes, particularly at six weeks, increased significantly, compared to those at two weeks; however, there was no statistically significant difference between the groups. In terms of the BMD measurement, they also found no significant difference between the groups. In our study, we measured the callus volumes and the cortex volumes in the fracture line, their ratio to each other, and the BMDs using the $\mathrm{mCT}$ device, which can provide a standard numerical way for the findings of radiological measurement and imaging. We found that both doses of vardenafil significantly increased the primary bone volume, particularly in the late period, although it did not significantly affect BMD.

Three-point bending test is a widely used method to measure the biomechanical strength of the callus tissue. ${ }^{[18,19]}$ A valuable data on the bending forces can be obtained with this method; however, the lack of testing of rotational and shear forces is among the main limitations of the test. Nyman et al. ${ }^{[19]}$ investigated the effects of lovastatin on the fracture union and measured the structural stiffness, structural strength (maximum strength), and energy failure using this three-point bending test. In addition, they measured the total callus volume and mineralized callus volume with $\mathrm{mCT}$ and showed that these values were inversely proportional to the callus strength and stiffness. In another study, Prodinger et al. ${ }^{[20]}$ used this bending test in a study in which they investigated the biomechanical behavior and radiological characteristics of bones of different lengths in rats and showed that the ideal bone that could be measured biomechanically with this test was long bones. As a result of the biomechanical analysis in the present study, both doses of vardenafil at six weeks were found to increase the maximum bone fracture strength significantly, compared to the control group; however, no significant difference was found between the two doses. In addition, there was no significant difference between the BMD values of the groups according to the $\mathrm{mCT}$ findings. Therefore, these findings indicate that there is no strong relationship between the biomechanical data and BMD.

According to the histopathological data, although mostly fibrous tissue and a small amount of cartilage were observed in the soft callus areas in the control group in the early period, more cartilage tissue and even a small amount of immature bone were found in vardenafil-administered rats. By the sixth week, due to the natural fracture healing process, the cartilage tissues and a small amount of immature bone were observed in the soft callus areas of the control group, while the cartilage and immature bone were found in equal amounts in the callus areas of rats treated with low-dose vardenafil. Histopathological scores increased in rats treated with high doses of vardenafil, in other words, predominantly immature bone and a small amount of cartilage were observed in the callus areas, and even the fracture line was completely closed in some rats and covered with immature bone. Therefore, the fact that vardenafil induces the fracture healing and increases the strength of the fracture line may be related to its contribution to the formation of hard callus.

Clarifying the cellular and biochemical events of the fracture healing process has been a guide in investigating the effects of many physical and biological factors on fracture healing. To understand the roles of these processes in the positive effects of vardenafil at tissue level, we performed immunohistochemical analyses of iNOS, TGF-3, and $\mathrm{NF}-\kappa \mathrm{B}$ proteins. It was previously demonstrated that sildenafil was an anti-inflammatory and neuroprotective agent in rodents, acting through the NOS-NO-cGMP-IK $\beta \alpha-N F \kappa B$ pathway in neuroinflammation. ${ }^{[21]}$ A study by Abdel Aziz et al. ${ }^{[22]}$ conducted in the diabetic rats showed that tadalafil influenced the erectile function by increasing cGMP levels, expression of NOS enzymes, and decreasing $\mathrm{NF}-\kappa \mathrm{B}$ expression levels. In a rat fracture model established in the present study, we found that a high dose of vardenafil significantly reduced NF- $\kappa \mathrm{B}$ 
immunopositivity in the early period, compared to the control group, although the effects in the late period returned to the same levels of the control group. Therefore, we consider that the effects of vardenafil on the NF- $\mathrm{BB}$ pathway in fracture healing can be only exerted in the early period. Further molecular studies using different doses may reveal the role of NF- $\kappa B$ pathway mediating the effects of vardenafil and other factors in the fracture healing process.

Vardenafil is a PDE5 inhibitor which catalyzes cGMP degradation and promotes smooth muscle relaxation. It is known to cause NO-induced cGMP accumulation and subsequent vasodilation. It has also been shown that intracellular cGMP accumulation reduces the oxidative stress in tissue, exerting antioxidative effects. The NO is a common radical in the site of fracture healing and inflammation. ${ }^{[23]}$ Vardenafil increases and contributes to the blood flow to the fracture healing site owing to its effects on the NO production pathway. ${ }^{[3]}$ In the immunohistochemical iNOS analysis, we found that both doses of vardenafil increased the iNOS immunopositivity in the early period of the fracture, but lost its effect in the late period of recovery. This suggests that vardenafil is effective in early stages, when the vasodilation is most needed in the fracture healing process, but later this effect disappears with primary bone formation.

The TGF- $\beta$ released into the environment following the activation of cytokines during the inflammation phase, which is the first stage of fracture healing, stimulates the mesenchymal cells for the production of type 2 collagen and structural proteoglycan, and the osteoblast cells for collagen production. ${ }^{[2]}$ It is abundant in the hematoma formed in the fracture line and effective on the cartilage and bone matrix synthesis. It has also chemotaxis properties in the bone tissue cells. Additionally, it stimulates the fibronectin production and matrix storage in the bone tissue. ${ }^{[25]}$ To the best of our knowledge, there is no study showing the PDE5 inhibitor's role in the fracture healing via the TGF pathway. In this study, according to the immunohistochemical findings, we showed that TGF- $\beta 3$ was effective, particularly in the first phase of fracture healing, and vardenafil increased this effect significantly; however, TGF- $\beta 3$ returned to the normal levels in the late period. This finding suggests that TGF- $\beta 3$ expression may increase with the increase of inflammation, and vardenafil may accelerate the fracture healing by elevating the expression.
In the current study, the comparisons for two different doses of vardenafil demonstrated no statistically significant difference in terms of the radiological, biomechanical and histomorphometric findings. However, the histological healing scores were found to be significantly different in the high-dose group in the late period, compared to the low-dose group; however, no such difference was observed in the early period. Similarly, the inflammation in high dose group in the late period significantly decreased and even completely disappeared compared to the low-dose group, while no statistically significant difference was found between the doses in the early period. According to the immunohistochemical findings, a significant decrease in NF- $\kappa \mathrm{B}$ immunopositivity was detected only in high-dose group in the early period, while no statistically significant difference was found between the dose groups in terms of iNOS and TGF- $\beta 3$ reactivity in both periods.

There were some limitations in our study. Since the surgical fracture model was chosen, the fracture hematoma, which is very important in the early stages of fracture union, was removed from the fracture site. Secondly vardenafil doses have been determined based on doses studied in the literature, therefore a complete optimization has not been achieved. Finally, statistical analysis could only be performed in relatively small groups, since the lowest possible number of animals was used when determining the number of animals in the groups.

In conclusion, this study demonstrates that, during the fracture healing process, vardenafil has positive effects on the bone healing radiologically, biomechanically, histopathologically, histomorphometrically, and immunohistochemically, particularly in the early period, when the vasodilation is more needed, and the inflammation occurs. Although vardenafil showed positive effects on fracture healing at the doses we selected in this study, further studies are needed to establish the most optimal dose.

\section{Declaration of conflicting interests}

The authors declared no conflicts of interest with respect to the authorship and/or publication of this article.

\section{Funding}

The authors received no financial support for the research and/or authorship of this article.

\section{REFERENCES}

1. Karaduman ZO, Arıcan M, Turhan Y, Turhal O, Orhan Z, Gamsızkan M. Systemic tranexamic acid promotes bone healing in a rat model of femur fracture. Jt Dis Relat Surg 2020;31:432-9. 
2. Tzioupis C, Giannoudis PV. Prevalence of long-bone nonunions. Injury 2007;38 Suppl 2:S3-9.

3. Toğral G, Arıkan M, Korkusuz P, Hesar RH, Ekşioğlu MF. Positive effect of tadalafil, a phosphodiesterase- 5 inhibitor, on fracture healing in rat femur. Eklem Hastalik Cerrahisi 2015;26:137-44.

4. Gur S, Kadowitz PJ, Serefoglu EC, Hellstrom WJ. PDE5 inhibitor treatment options for urologic and non-urologic indications: 2012 update. Curr Pharm Des 2012;18:5590-606.

5. Carson CC, Lue TF. Phosphodiesterase type 5 inhibitors for erectile dysfunction. BJU Int 2005;96:257-80.

6. Kass DA, Takimoto E, Nagayama T, Champion HC. Phosphodiesterase regulation of nitric oxide signaling. Cardiovasc Res 2007;75:303-14.

7. Grimsley SJ, Khan MH, Jones GE. Mechanism of Phosphodiesterase 5 inhibitor relief of prostatitis symptoms. Med Hypotheses 2007;69:25-6.

8. Dincel YM, Alagoz E, Arikan Y, Caglar AK, Dogru SC, Ortes F, et al. Biomechanical, histological, and radiological effects of different phosphodiesterase inhibitors on femoral fracture healing in rats. J Orthop Surg (Hong Kong) 2018;26:2309499018777885.

9. Histing T, Marciniak K, Scheuer C, Garcia P, Holstein JH, Klein $\mathrm{M}$, et al. Sildenafil accelerates fracture healing in mice. J Orthop Res 2011;29:867-73.

10. Sahara M, Sata M, Morita T, Nakajima T, Hirata $Y$, Nagai R. A phosphodiesterase-5 inhibitor vardenafil enhances angiogenesis through a protein kinase G-dependent hypoxiainducible factor-1/vascular endothelial growth factor pathway. Arterioscler Thromb Vasc Biol 2010;30:1315-24.

11. Huo MH, Troiano NW, Pelker RR, Gundberg CM, Friedlaender GE. The influence of ibuprofen on fracture repair: Biomechanical, biochemical, histologic, and histomorphometric parameters in rats. J Orthop Res 1991;9:383-90.

12. Teke K, Yaprak Bayrak B, Yuksekkaya M, Uslubas AK, Kosem ME, Yilmaz $\mathrm{H}$, et al. Prognostic value of immunological profile based on CD8+ and FoxP3+ $\mathrm{T}$ lymphocytes in the peritumoral and intratumoral subsites for renal cell carcinoma. Int Urol Nephrol 2020;52:2289-99.

13. Gerstenfeld LC, Wronski TJ, Hollinger JO, Einhorn TA. Application of histomorphometric methods to the study of bone repair. J Bone Miner Res 2005;20:1715-22.

14. Ertürküner SP, Yaprak Saraç E, Göçmez SS, Ekmekçi $\mathrm{H}$, Öztürk ZB, Seçkin İ, et al. Anti-inflammatory and ultrastructural effects of Turkish propolis in a rat model of endotoxin-induced uveitis. Folia Histochem Cytobiol 2016;54:49-57.

15. Yaman F, Atilgan S, Günes N, Agacayak S, Günay A, Ucan MC, et al. Phosphodiesterase-5 inhibitors may facilitate bone defect recovery. Eur Rev Med Pharmacol Sci 2011;15:1301-5.

16. Göktürk E, Turgut A, Bayçu C, Günal I, Seber S, Gülbas Z. Oxygen-free radicals impair fracture healing in rats. Acta Orthop Scand 1995;66:473-5.

17. Kaygusuz MA, Ataşlı N, Aydoğdu İ, Özen S, Elmalı N, Şarlak Ö. GM-CSF'nin kırık iyileşmesi uzerine etkisinin sıçan tibiaları üzerinde araştırılması. Acta Orthop Traumatol Turc 1999;33:205-10.

18. Rajfer RA, Kilic A, Neviaser AS, Schulte LM, Hlaing SM, Landeros J, et al. Enhancement of fracture healing in the rat, modulated by compounds that stimulate inducible nitric oxide synthase: Acceleration of fracture healing via inducible nitric oxide synthase. Bone Joint Res 2017;6:90-7.

19. Nyman JS, Munoz S, Jadhav S, Mansour A, Yoshii T, Mundy GR, et al. Quantitative measures of femoral fracture repair in rats derived by micro-computed tomography. J Biomech 2009;42:891-7.

20. Prodinger PM, Foehr P, Bürklein D, Bissinger O, Pilge H, Kreutzer $\mathrm{K}$, et al. Whole bone testing in small animals: Systematic characterization of the mechanical properties of different rodent bones available for rat fracture models. Eur J Med Res 2018;23:8.

21. Nunes AK, Rapôso C, Rocha SW, Barbosa KP, Luna RL, da Cruz-Höfling MA, et al. Involvement of AMPK, IK $\beta \alpha-N F \kappa B$ and eNOS in the sildenafil anti-inflammatory mechanism in a demyelination model. Brain Res 2015;1627:119-33.

22. Abdel Aziz MT, Rezq AM, Atta HM, Fouad H, Zaahkouk AM, Ahmed $\mathrm{HH}$, et al. Molecular signalling of a novel curcumin derivative versus Tadalafil in erectile dysfunction. Andrologia 2015;47:616-25.

23. Corbett SA, Hukkanen M, Batten J, McCarthy ID, Polak JM, Hughes SP. Nitric oxide in fracture repair. Differential localisation, expression and activity of nitric oxide synthases. J Bone Joint Surg [Br] 1999;81:531-7.

24. Bostrom MP, Asnis P. Transforming growth factor beta in fracture repair. Clin Orthop Relat Res 1998;(355 Suppl):S124-31.

25. Dohan Ehrenfest DM, Rasmusson L, Albrektsson T. Classification of platelet concentrates: From pure plateletrich plasma (P-PRP) to leucocyte- and platelet-rich fibrin (L-PRF). Trends Biotechnol 2009;27:158-67. 